\title{
Health and health equity among rural poor residents in the context of China's targeted poverty alleviation policy: evidence from Shaanxi province
}

\section{Xiuliang Dai}

School of Public Policy and Administration,Xi'an Jiaotong University

Lijian Wang ( $\square$ wanglijian2@163.com )

School of Public Policy and Administration,Xi'an Jiaotong University

Yangling Ren

School of Public Policy and Administration,Xi'an Jiaotong University

Research article

Keywords: Targeted poverty alleviation policy, Rural poor residents, Health equity, Concentration index, Decomposition of the concentration index

Posted Date: March 3rd, 2020

DOl: https://doi.org/10.21203/rs.3.rs-15694/v1

License: (c) (i) This work is licensed under a Creative Commons Attribution 4.0 International License. Read Full License 


\section{Abstract}

Background: China's targeted poverty alleviation policy is having a profound impact on the country's rural economic and social development now. This study aimed to learn about the health status and health equity of rural poor residents under the implementation of the policy. It further explores the factors affecting the health status and health equity of rural poor residents, in order to contribute to the improvement of the policy.

Methods: Data from 1,233 rural poor residents were derived from a questionnaire survey from 12 prefecture-level cities and areas of Shaanxi province in 2017, and a self-evaluation of health was used to reflect the health status. A concentration index was applied to measure the inequity of the health status of rural poor residents. The decomposition method was employed to explore the source of health inequity.

Results: The results showed that $44.56 \%$ of rural poor residents in Shaanxi province had a poor or very poor health status, which was affected by their economic level, gender, age, the degree of education, and marital status. Additionally, participation in industry development, relocation, health poverty alleviation, and basic living standards were significantly correlated with the health status. The concentration index of the health status of rural poor residents in Shaanxi province was 0.0327 . The primary contributors to the health inequity in different regions varied, but the economic level and the degree of education were the most significant factors, and the targeted poverty alleviation policy had a significant impact on the health equity.

Conclusions $\mathbb{Q}$ The results indicated that the health status of rural poor residents in Shaanxi province was generally poor, there was a pro-rich inequity in the health status, and the degree of education and economic level were the primary factors affecting the health status and health equity. The targeted poverty alleviation policy greatly impacted the health status and health equity, and the difference in health status would lead to the inequity of benefits of the targeted poverty alleviation policy. In the future, the policy should focus on ensuring the sustainable development ability of rural residents with poor health status.

\section{Background}

Health is not only a direct component of the well-being of humans but also a human capital that increases the development capacity of individuals, families, and society [1]. There is a close relationship between health and poverty, and poor residents with a poor health status due to the lack of health investment and access to health care, leads to the exacerbation of their own poverty. Previous studies have shown that lower socioeconomic levels tend to reduce residents' enthusiasm to invest in health, and groups with lower socioeconomic status tend to face higher health risks [2]. Therefore, the development of public health through national systems and policies plays an important role in promoting individual health and eliminating poverty [3].At the same time, ensuring the health equity of different social and 
economic status groups has always been an important goal of medical and health system reforms in various countries. Health equity is an important part of social equity and justice, which is the basis of ensuring that different groups have equal access to resources and viability [4].

For a long time, the Chinese government has made great efforts to promote the health of citizens and eliminate poverty. The most striking is China's targeted poverty alleviation policy in the new era. Since 2013, China's targeted poverty alleviation strategy has become an important tool and source of power to help rural poor residents shake off poverty and build a moderately well rounded prosperous society. Targeted poverty alleviation means to promote the income, living standards, and health of rural poor residents through comprehensive poverty reduction measures. "The 13th five-year plan for poverty alleviation (2016)" has set the development goals of "ensuring that the rural poor have enough food and clothing under the current standards, and that compulsory education, basic medical care and housing are secure". We have formulated a targeted poverty alleviation policy system consisting of developing competitive industries, locating jobs elsewhere, relocation, improving education, providing better healthcare, better ecological protection, guaranteeing basic living standards, and social poverty alleviation, which was listed in Table 1. At the same time, according to the policy, poor residents who have already achieved the goal of poverty alleviation can still enjoy the targeted poverty alleviation policy by 2020 . Rural poor residents refer to the poverty-stricken family members that meet the standards of poor households in the targeted poverty alleviation policy and have been accurately identified by the government. According to a report by China's national bureau of statistics, by the end of 2018, the number of people living in poverty in rural China had dropped from 98.99 million at the end of 2012 to 16.6 million, and the poverty rate had dropped from $10.2 \%$ to $1.7 \%$. The targeted poverty alleviation strategy plays a significant role in promoting economic development, environmental improvement, social progress, and the improvement of people's living standards in rural poverty-stricken areas, which expands the identification and targeting of anti-poverty in rural areas from a single income dimension to multiple dimensions such as income, education, health, and living standards. The policy establishes a comprehensive, accurate and long-term poverty alleviation mechanism, which demonstrates China's strong capacity for national governance and the socialist nature of eradicating poverty, improving people's livelihood and achieving common prosperity [5].

Table 1 Main policy systems and measures of poverty alleviation in the 13th five-year plan 


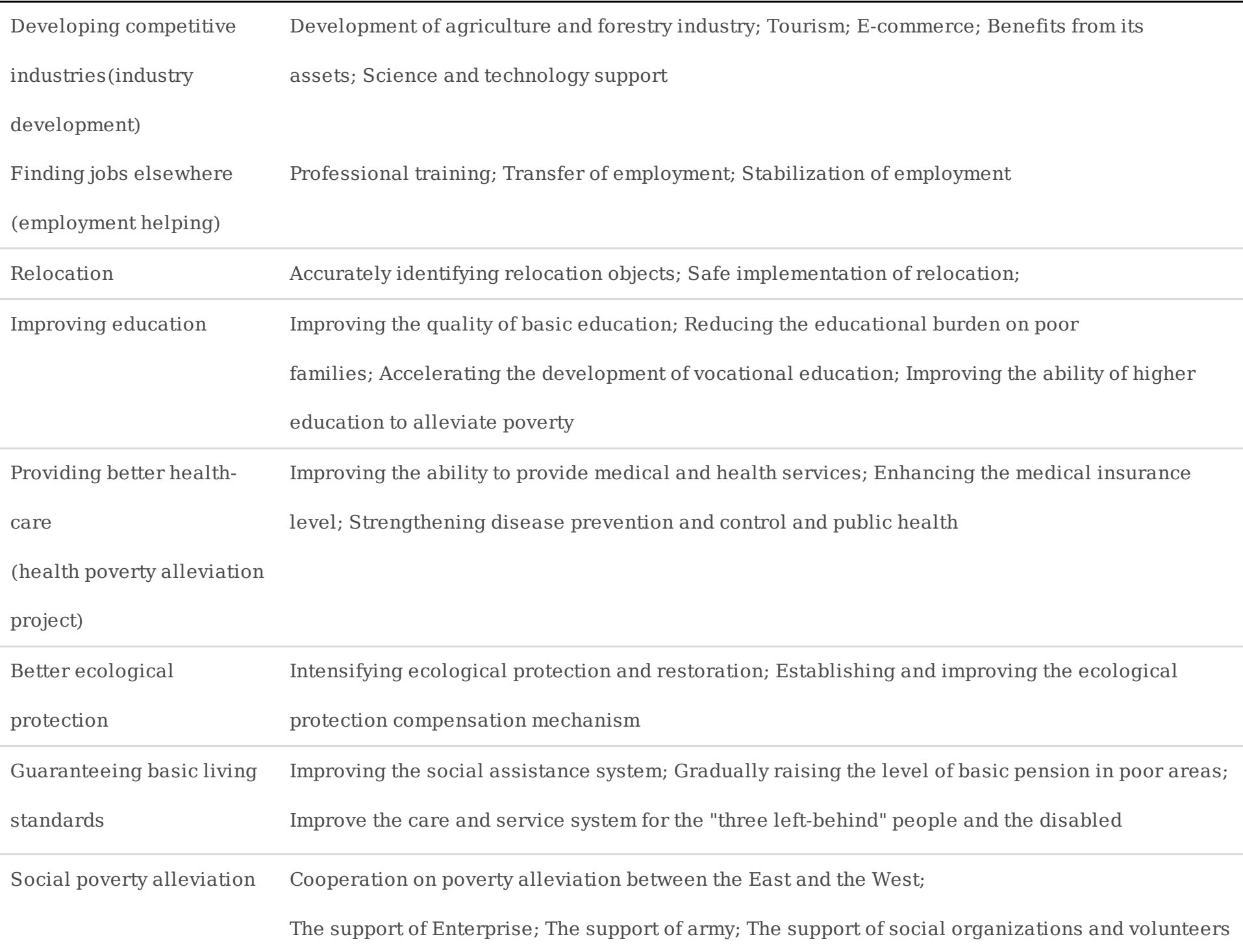

However, another important fact is that Poverty due to disease is an important cause of poverty of rural residents in China. Over time there has been a great difference between urban and rural economic development and insufficient investment in rural public health services, leading to health problems and poverty within rural residents in China [6]. In 2019, 40\% of China's 16.6 million rural poor residents are being impoverished or returning to poverty due to illness. The targeted poverty alleviation policy not only increases the income of rural poor residents, but also reduces their medical burden, which has a profound impact on improving their health status. Since the implementation of the targeted poverty alleviation policy in 2013, the production and living conditions of some poor residents has undergone significant changes under the policy. But due to the influence of personal and family development ability and other factors, the policy benefits will differ between residents. Poor residents with poor health status may become the focus of the targeted poverty alleviation policy because of the dual pressure of economic income growth and health improvement. From the perspective of policy development, the impact of the targeted poverty alleviation policy on poor residents is multi-faceted. Ensuring the fairness of benefits for 
poor residents is also an important principle for the implementation of the targeted poverty alleviation policy, therefore it is important to focus on the health and health equity of the rural poor residents.

Although, previous research had paid some attention to the China's targeted poverty alleviation policies, the health and health equity of the rural poor residents under the policy have not been addressed. The previous research focused on the following aspects. First, it explores relevant policy innovations such as land policies in the implementation process of the targeted poverty alleviation strategy $[7,8]$. Second, the implementation effect of the targeted poverty alleviation policy is evaluated based on different perspectives and methods [9-12]. Third, it analyzes the challenges and innovation paths of the implementation of the targeted poverty alleviation policy $[13,14]$. Meanwhile, researchers have made full research on China's rural medical policies and effects.[15,16,17]. But there is still a lot of research gap on the health and health equity of poor rural residents in China under the background of targeted poverty alleviation. Health and poverty is always a hot research top. The China's targeted poverty alleviation policy offer a new chance to research this interesting question. However, this important problem has not attracted the enough attention of researchers.

Therefore, this study uses the data from rural poor residents in Shaanxi province from 2017 to describe and analyze the health status and health equity of rural poor residents. Shaanxi province is a key region for the implementation of China's targeted poverty alleviation strategy. And by the end of 2018, there are still 29 poverty-stricken counties with 775,500 poor residents. And affected by the natural environment, Shaanxi province is divided into three regions: Shanbei, Guanzhong and Shannan. Shanbei is the loess plateau, Guanzhong is the plain, and Shannan is the mountainous area, and the economic and social development levels of the three regions are quite different. so, it is also necessary to analyze the health status and health equity of rural poor residents from the perspective of regional difference. The identification standards for poor residents in Shaanxi province include: first, the net per capita annual income of residents is less than 3,070 yuan; Second, food and clothing (including safe drinking water) are not guaranteed, and compulsory education, basic medical care, and housing security have not been effectively addressed. In addition, the data will explore the influencing factors of health equity, which is conducive to improving the implementation of the targeted poverty alleviation and promoting the health equity of rural residents. Health equity is a very rich concept, which involves many aspects of health status, needs, and utilization of health services [18]. This study focuses on the equity of health status to see if different rural poor residents have the same health status.

\section{Methods}

\section{Data collection and quality control}

\section{Organization and implementation}

The research team carried out a questionnaire survey on rural poor residents in Shaanxi province by recruiting students on the summer holiday social practice program for college students of Xi'an Jiaotong University in 2017. The summer social practice program for college students is organized and 
implemented by the youth league committee of Xi'an Jiaotong University. The university, together with 12 cities and districts of Shaanxi province, has established a social practice base for college students. Every summer holiday, the university will send outstanding college students to various cities and districts to work as interns in township party, government organizations, and public institutions under its jurisdiction. The research team recruited these college students as investigators to implement the questionnaire survey, and these students from the same county made up the survey team. The questionnaire included basic information of rural poor residents such as health status, income, age, the degree of education, gender and marital status, their living conditions, and their participation in the targeted poverty alleviation policy.

\section{Sampling method}

First, a three-stage sampling survey method combining probability and non-probability sampling was adopted. We selected counties (districts) with rural areas from 12 municipals in Shaanxi province, and the typical rural administrative village was selected in the counties (districts). Last, each rural village randomly selected six eligible poor households as the subject of survey. The sampling process was carried out by each survey team in accordance with scientific, typical, and convenient principles.

\section{Data quality control}

First, the college students from the social practice that participated in the survey were trained ahead of time, the structure and content of the questionnaire were explained, and the matters needing attention and principles in the questionnaire survey were emphasized. Second, every member of this survey can use the survey data to conduce a research so that they will be more responsible. Third, A preliminary investigation was conducted and the questionnaire was revised according to the problems found in the preliminary survey so that the scientificity of the formal questionnaire was guaranteed. Fourth, we used one-to-one interview to answer the questionnaire, which means that our investigators ask the rural poor residents and fill out questionnaires based on the answer. And problems existing in the survey were solved timely through network communication during the implementation of the survey. Last, we checked the questionnaires the students returned. According to the general requirements of social survey, the questionnaires is valid if there is no logic error and the main questions had been answered. After Eliminating questionnaires that lack key information such as health status, income, age, the degree of education, gender and marital status, a total of 1,233 valid samples were obtained after removing the samples under the age of 16 .

\section{Description of the health status of rural poor residents}

Descriptive statistical analysis was used to describe the health status of rural poor residents, and chisquare test was used to analyze whether there were statistically significant differences in the health status of poor residents in different regions.

\section{Measurement of health equity}


A simple way to measure health equity is to test whether two groups (the poor and the rich) have the same health level. Currently, there are many methods to measure health equity, including the method of concentration curve and concentration index, method of Lorenz curve and gini-coefficient Lorenz curve, atkinson index, and chi-square value Method [19]. Although the method of concentration index and lorenz curve and gini coefficient is similar to the way of expression. The concentration index not only provides an indicator of health inequity but can also be decomposed proportionally into contributions of different inequity of health determinants[20]. Referring to existing studies on health equity of Chinese residents $[21,22]$, this research uses the centralized index method to measure the health equity of rural poor residents. The concentration index is used to investigate the inequity degree of a certain variable associated with social and economic status, which dynamically reflects the effect of the variable influenced by income [23]. The concentration index is calculated using Equation 1 [21].

$$
C=\frac{2}{u} \operatorname{cov}(y, r)
$$

where $\mathrm{C}$ is concentration index, $y$ is health status, $u$ is the mean of health status, $r$ is the fractional rank of income, ranging from 0 to 1 . The value of the concentration index is -1 to 1 . If the concentration index is 0 , this shows that rural poor residents with different economic levels have the same health status. $A$ positive concentration index indicates that people with higher incomes are healthier than those with lower incomes. Conversely, a negative concentration index indicates that people with lower incomes are healthier than those with higher incomes.

The method of decomposition of the concentration index is used to analyze the contributions of various determinants of health to the inequity in health status. Decomposition of the concentration index is proposed by Wagstaff, which is a straightforward way to decompose the measured degree of inequity into the contributions of various explanatory factors [24]. The positive value of contribution means that the variable contributes to pro-rich inequity, that is, richer individuals have a better health status than the poor, and vice versa [20]. We use the OLS linear regression to decompose the health inequity of rural poor residents, because the health status of rural poor residents is a count variable. First, a regression model should be given as Equation 2.

$$
y_{i}=\alpha+\beta_{m} x^{m}+\sum_{n} \beta_{n} x_{i}^{n}+\sum_{n} \beta_{p} x_{i}^{p}+\varepsilon_{i}
$$

Where $y_{i}$ is the health status; $x^{m}$ is income; $x^{n}$ are need variables; $x^{p}$ are other variables; $\beta_{m}, \beta_{n}$ and $\beta_{p}$ are coefficients; $\varepsilon_{i}$ is the implied error term, which includes approximation errors. Then the concentration index for $y$ can be written as Equation 3:

$$
\hat{C}=\left(\beta_{m} \bar{x}_{m} / \bar{y}\right) \hat{C}_{m}+\sum_{n}\left(\beta_{n} \bar{x}_{n} / \bar{y}\right) \hat{C}_{n}+\sum_{p}\left(\beta_{p} \bar{x}_{p} / \bar{y}\right) \hat{C}_{p}+G C_{\varepsilon} / \bar{y}
$$

Where $\hat{C}$ is the concentration index of health status, and $\hat{C}_{m}, \hat{C}_{n}$, and $\hat{C}_{p}$ are the 
concentration indexes of $x^{m}, x^{n}$, and $x^{p}$. The terms on the right side of Equation 3 denotes the contributions of income, need variables, other variables, and the implied error to inequity.

\section{Variables}

\section{Outcome variable}

Health is a complex concept, so there are many methods and indicators to measure the health status of residents. The European five-dimensional health scale (EQ-5D) is widely used by researchers due to its simplicity and high credibility [25-27]. Zhang divided the health of the elderly into three aspects: physical health, cognitive function, and self-evaluated health [28]. Li measured the health status of rural Chinese residents by whether they had been ill in the past two weeks and whether they suffered from chronic diseases [29]. Meanwhile, Lorraine et al. thought that Self-rated health is generally accepted as a valid measure of health status in population studies in their research[30], and Hesketh et al. used the self-rated health explored the health status and access to health care of migrant workers in China[31]. Taking the experience that using self-reported health to measure the health status of people for reference, this study thinks that Self-rated health status can accurately and directly reflect rural poor residents' understanding of their overall health status, including Both physical health and mental health. Therefore, this study reflects the health status of rural poor residents through self-reported health questionnaires. The selfevaluation questions about health is "how do you feel about your physical health?", and the answer includes five dimensions of very poor, poor, average, good, and very good, with a value of 1-5.

\section{Independent variables}

Since this study uses the method of centralized exponential decomposition to analyze the influencing factors of health equity, the independent variables in this study include three categories: income, need variables, and other variables. Income is measured by self-reported annual household income. Due to the process of targeted poverty alleviation, the financial sources of poor households may be diverse. In the process of the survey, the surveyor will specifically ask whether there are government subsidies and other policy incomes to ensure the accuracy of income. Need variables are closely related to the definition of health equity. In this study, need variables include gender, age, education level, and marital status of rural poor residents. Other variables mainly refer to the targeted poverty alleviation policies that may have an impact on the health and health equity of poor residents. Taking into account the impact of policies and the participation situation of poor residents, the targeted poverty alleviation policies researched in this study include industry development, relocation, employment helping, health poverty alleviation project, and basic living standard guaranteeing. The variable descriptions are shown in Table 2.

Table 2 Socio-demographic characteristics of rural poor residents and variables descriptions 


\begin{tabular}{|c|c|c|c|c|c|}
\hline variables & $\begin{array}{c}\text { Shannxi province } \\
(\mathrm{N}=1233)\end{array}$ & $\begin{array}{l}\text { Shanbei } \\
(\mathrm{N}=240)\end{array}$ & $\begin{array}{l}\text { Guanzhong } \\
(\mathrm{N}=664)\end{array}$ & $\begin{array}{l}\text { Shannan } \\
(\mathrm{N}=329)\end{array}$ & $\mathbf{P}$ \\
\hline & $\mathrm{n}(\%)$ & $\mathrm{n}(\%)$ & $\mathrm{n}(\%)$ & n(\%) & \\
\hline
\end{tabular}

\section{Health status}

\begin{tabular}{|c|c|c|c|c|}
\hline Very poor & $170(14.98)$ & $12(5.00)$ & $110(17.13)$ & $48(14.77)$ \\
\hline Poor & $357(29.58)$ & $31(12.92)$ & $213(33.18)$ & $113(34.77)$ \\
\hline Medium & $393(32.56)$ & $131(54.58)$ & $164(25.55)$ & $98(30.15)$ \\
\hline Well & $265(21.96)$ & $60(25.00)$ & $144(22.43)$ & $61(18.77)$ \\
\hline Very well & $22(1.82)$ & $6(2.50)$ & $11(1.71)$ & $5(1.54)$ \\
\hline
\end{tabular}

\begin{tabular}{llllll} 
Income & $13395.11 \pm 374.99$ & $13770.86 \pm 1243.304$ & $14001.7 \pm 432.80$ & $11580 \pm 531.54$ & 0.029 \\
\hline Gender & & & &
\end{tabular}

\begin{tabular}{cccccc}
\hline Male & $911(74.13)$ & $161(67.08)$ & $528(79.88)$ & $222(67.68)$ & 0.000 \\
\cline { 1 - 3 } Female & $318(25.87)$ & $79(32.92)$ & $133(20.12)$ & $106(32.32)$
\end{tabular}

Age

\begin{tabular}{|c|c|c|c|c|}
\hline Age $<31$ & $69(5.60)$ & $15(6.25)$ & $37(5.57)$ & $17(5.17)$ \\
\hline $30<$ Age $<61$ & $806(65.37)$ & $176(73.33)$ & $439(66.11)$ & $191(58.05)$ \\
\hline Age $>60$ & $358(29.03)$ & $49(20.42)$ & $188(28.31)$ & $121(36.78)$ \\
\hline
\end{tabular}

Degree of education

\begin{tabular}{|c|c|c|c|c|c|}
\hline Unschooled & $389(31.99)$ & $155(64.58)$ & $130(20.00)$ & 104(31.90! & 0.000 \\
\hline Primary school & $439(36.10)$ & $55(22.92)$ & $267(41.08)$ & 117ロ35.89ם & \\
\hline Middle school and above & $388(31.91)$ & $30(12.50)$ & 253(38.92) & $105 \square 32.21 \square$ & \\
\hline \multicolumn{6}{|l|}{ Marital status } \\
\hline Unmarried & $150 \square 12.44 \square$ & $10(4.17)$ & $102(15.91)$ & $38(11.69)$ & \multirow[t]{3}{*}{0.000} \\
\hline Married and cohabiting & 843ロ69.90ロ & $202(84.17)$ & $428(66.77 \square$ & $213(65.54)$ & \\
\hline Divorced or widowed & 213(17.66) & 28(11.67) & $111 \square 17.32 \square$ & $74 \llbracket 22.77 \square$ & \\
\hline \multicolumn{6}{|c|}{ Participation in industry development } \\
\hline No & $399(36.84)$ & $52(21.67)$ & $250(42.52)$ & $97(38.04)$ & \multirow[t]{2}{*}{0.000} \\
\hline Yes & $684(63.16)$ & $188(78.33)$ & $338(57.48)$ & 158(61.96) & \\
\hline \multicolumn{6}{|l|}{ Participation in relocation } \\
\hline No & $841(82.21)$ & $207(86.25)$ & $441(79.03)$ & 193(85.78) & \multirow[t]{2}{*}{0.014} \\
\hline Yes & $182(17.79)$ & $33(13.75)$ & $117(20.97)$ & $32(14.22)$ & \\
\hline
\end{tabular}

participation in employment helping 


\begin{tabular}{cccccc} 
No & 823(81.32) & $191(79.58)$ & $459(81.67)$ & $173(82.38)$ & 0.712 \\
\cline { 1 - 2 } Yes & $189(18.68)$ & $49(20.42)$ & $103(18.33)$ & $37(17.62)$ \\
\hline
\end{tabular}

Enjoying the health poverty alleviation project

\begin{tabular}{cccccc}
\hline No & $292(26.43)$ & $72(30.00)$ & $189(32.53)$ & $31(10.92)$ & 0.000 \\
Yes & $813(73.57)$ & $167(70.00)$ & $392(67.47)$ & $253(89.08)$ & \\
\hline Enjoying basic living standard guaranteeing & & & & \\
\hline No & $463(44.18)$ & $108(45.00)$ & $310(54.20)$ & $45(19.07)$ & 0.000 \\
\hline Yes & $585(55.82)$ & $132(55.00)$ & $262(45.80)$ & $191(80.93)$ \\
\hline
\end{tabular}

\section{Results}

\section{General characteristics of rural poor residents}

Table 2 shows the socio-demographic characteristics of the sample and the participation of rural poor residents in Shaanxi province using the targeted poverty alleviation policy. We surveyed 1,233 rural poor residents over the age of 15 in Shaanxi province, among whom $74.13 \%$ were males and $25.87 \%$ were females. In terms of age distribution, those aged between 16 and 30 accounted for $5.60 \%$, those aged between 31 and 60 accounted for $65.37 \%$, and those aged over 60 account for $29.03 \%$. In the education category, the degree of primary school had the largest proportion of $36.10 \%$, followed by rural poor residents who had never attended school at $31.99 \%$, and finally, those with degrees from junior high school or above accounted for $31.91 \%$. In terms of marital status, $12.44 \%$ of the rural poor residents are unmarried, and $17.66 \%$ are divorced or widowed. Among residents, $14.98 \%$ are said to be in very poor health status, $29.58 \%$ are in poor health status, $32.56 \%$ are in medium health status, and those with good or very good health status accounted for $23.78 \%$. The average annual household income of rural poor residents is about $13395.11 \pm 374.99$ yuan. According to the participation of rural poor residents in the targeted poverty alleviation policy, $63.16 \%$ had participated in the industry development, $17.79 \%$ had enjoyed the relocation poverty alleviation policy, $18.68 \%$ had enjoyed the employment helping policy, $73.57 \%$ had enjoyed the health poverty alleviation policy, and those who enjoyed the basic living standard guaranteeing policy accounted $55.82 \%$. Of the residents, everyone is entitled to enjoy one or more of these targeted poverty alleviation policies.

\section{Comparison of health status of rural poor residents under different socio-demographic characteristics}

Table 3 shows the health status of rural poor residents in Shaanxi province under the circumstances of different regions, income levels, gender, age, education level, marriage, and participation in the targeted poverty alleviation, where the chi-squared statistic method is used to test the health status differences. The health status of rural poor residents in varying regions was significantly different. The proportion of rural poor residents with a good health status and very good health status in Shanbei was significantly higher than that in Shannan and Guanzhong. Under different family income levels, the health status of 
rural poor residents had significant differences, the proportion of poor income status with poor health status was $17.28 \%$, the proportion of medium income status with poor health status was $16.31 \%$, and the proportion of good income status with poor health status was $9.82 \%$. There was a significant difference between male and female health status, the proportion of male residents with general health status or above was $55.06 \%$, while the corresponding proportion of female residents was $59.69 \%$. The health status of poor residents in different age groups was significantly different. The proportion of poor health status of rural poor residents over 60 years old is $62.54 \%$, which was significantly higher than that of rural poor residents under 60 years old. Rural poor residents with different education levels had different health conditions. The health status of rural poor residents with a junior high school education or above was significantly better than that of those without an education or primary school education. And rural poor residents who are married and cohabiting were in better health status than those who are unmarried, divorced, or widowed.

Table 3 Comparison of health status differences among rural poor residents (\%) 


\begin{tabular}{|c|c|c|c|c|c|c|}
\hline Health status & Very poor & Poor & Medium & Well & Very well & $\mathbf{P}$ \\
\hline \multicolumn{7}{|l|}{ Region } \\
\hline Shanbei & 5 & 12.92 & 54.58 & 25 & 2.5 & 0.000 \\
\hline Guanzhong & 17.13 & 33.18 & 25.55 & 22.43 & 1.71 & \\
\hline Shannan & 14.77 & 34.77 & 30.15 & 18.77 & 1.54 & \\
\hline \multicolumn{7}{|l|}{ Income } \\
\hline The poorer & 17.28 & 34.55 & 30.89 & 15.71 & 1.57 & 0.000 \\
\hline Medium & 16.31 & 28.37 & 28.61 & 24.59 & 2.13 & \\
\hline The better & 9.82 & 22.32 & 38.69 & 27.38 & 1.79 & \\
\hline \multicolumn{7}{|l|}{ Gender } \\
\hline Male & 15.06 & 29.89 & 30.34 & 22.81 & 1.91 & 0.070 \\
\hline Female & 11.43 & 28.89 & 38.73 & 19.37 & 1.59 & \\
\hline \multicolumn{7}{|l|}{ Age } \\
\hline Age $<31$ & 2.9 & 7.25 & 20.29 & 68.12 & 1.45 & 0.000 \\
\hline $30<$ Age $<61$ & 11.5 & 26.8 & 36.41 & 22.76 & 2.53 & \\
\hline Age $>60$ & 22.19 & 40.35 & 26.22 & 10.95 & 0.29 & \\
\hline \multicolumn{7}{|l|}{ Degree of education } \\
\hline Unschooled & 16.88 & 28.31 & 39.22 & 14.29 & 1.3 & 0.000 \\
\hline Primary school & 13.43 & 35.19 & 31.25 & 18.29 & 1.85 & \\
\hline Middle school and above & 12.14 & 24.29 & 27.65 & 33.59 & 2.33 & \\
\hline \multicolumn{7}{|l|}{ Marital status } \\
\hline Unmarried & 25.33 & 27.33 & 20 & 27.33 & 0 & 0.000 \\
\hline Married and cohabiting & 9.52 & 28.92 & 36.75 & 22.77 & 2.05 & \\
\hline Divorced or widowed & 23.58 & 32.55 & 25.94 & 15.57 & 2.36 & \\
\hline
\end{tabular}

Participation in industrial development

\begin{tabular}{lllllll} 
No & 26.88 & 27.89 & 28.14 & 15.58 & 1.51 & 0.000 \\
\cline { 1 - 4 } Yes & 6.79 & 27.47 & 37.37 & 26.44 & 1.92 &
\end{tabular}

Participation in relocation

\begin{tabular}{ccccccc}
\hline No & 16.07 & 25.48 & 35.12 & 21.55 & 1.79 & 0.006 \\
\cline { 1 - 4 } Yes & 7.26 & 34.64 & 30.73 & 25.14 & 2.23 & \\
\cline { 1 - 3 } & & & & &
\end{tabular}

participation in employment helping

No

$15.45 \quad 27.13 \quad 34.18 \quad 21.41$

$1.82 \quad 0.714$

Page 12/24 


\begin{tabular}{cccccccc}
\hline Yes & 11.41 & 27.17 & 36.41 & 22.83 & 2.17 & \\
$\begin{array}{c}\text { Enjoying the health poverty alleviation policy } \\
\text { No }\end{array}$ & & & & & \\
\hline Yes & 9.93 & 21.28 & 42.91 & 24.47 & 1.42 & 0.000 \\
\hline Enjoying basic living standard guaranteeing policy & & & & \\
\hline No & 16.13 & 31.28 & 30.3 & 20.44 & 1.85 & \\
\hline Yes & 6.49 & 24.68 & 39.39 & 27.92 & 1.52 & 0.000 \\
\hline & 21.48 & 30.41 & 29.55 & 16.49 & 2.06 & \\
\hline
\end{tabular}

Judging from the participation of rural poor residents from the targeted poverty alleviation policies, there was a significant correlation between participation in industry development and their health status. The health status of residents participating in industry development was significantly better than that of residents not participating in industry development. The proportion of those who participated in the relocation with good health status and very good health status was $25.14 \%$ and $2.23 \%$, while the corresponding proportion of those who did not participate in the relocation was $21.55 \%$ and $1.79 \%$. There was no significant relationship between participation in employment helping and rural poor residents' health status. There was a significant difference between the poor residents who enjoyed healthy poverty alleviation and those who did not, and the proportion of poor health of the former was $47.41 \%$, which was significantly higher than the latter's $31.21 \%$. There was a significant difference between the health status of rural poor residents who enjoyed the basic living standard guaranteeing policy and those who did not, a total of $51.89 \%$ of rural poor residents who were entitled to the basic living standard guaranteeing policy had very poor health, while the corresponding proportion of the poor residents who were not was $31.17 \%$. These results show that there is a close relationship between the health status of rural poor residents and poverty, and participation in poverty alleviation policies. Industry development and relocation are developmental policies from which healthier residents are more likely to benefit. However, health poverty alleviation and basic living standard guaranteeing are welfare-oriented policies, and the effect on poor residents with poor health is more obvious.

\section{Concentration index and decomposition of health inequity of rural poor residents}

The concentration index of the health status of rural poor residents in Shaanxi province and different regions is shown in Table 4. For the entire sample, according to the concentration index of the health status, there were inequities favoring those who are richer in Shanxi province (0.0327), and the concentration index of health status of rural poor residents in Shanbei (0.0068), Guanzhong (0.0593), and Shannan (0.0354) is all positive, which means there is a health status inequity sloped towards the richer. This shows that residents with a higher income status are more likely to have better health. In addition, compared with the concentration index of rural poor residents' health status in Guanzhong and 
Shannan, the concentration index of rural poor residents' health status in Shanbei is the smallest, which means that the health equity of rural poor residents in Shanbei is the most advanced.

Table 4 Concentration index of the health status of the rural poor in different regions

\begin{tabular}{ccccc}
\hline Living region & Concentration index & S.E. & \multicolumn{2}{c}{$95 \%$ CI } \\
& & & Lower & Upper \\
\hline Shannxi province & 0.0327 & 0.0065 & 0.0199 & 0.0455 \\
Shanbei & 0.0068 & 0.0100 & -0.0128 & 0.0264 \\
Guanzhong & 0.0593 & 0.0092 & 0.0412 & 0.0773 \\
Shannan & 0.0354 & 0.0143 & 0.0074 & 0.0635 \\
\hline
\end{tabular}

The decomposition of the health status inequity of the rural poor residents is shown in Table 5. The known variables contributed $120.3169 \%$ to the inequity of the health status of rural poor residents, and the residual contribution rate was $59.2570 \%$. Among the variables, the most significant contributors to health status inequity of rural poor residents were the degree of education, region, marital status, and age. The degree of education had the highest contribution rate of $32.5702 \%$ and a contribution value of 0.0106 , indicating that the degree of education increased the inequity of health status which sloped towards the richer. The contribution rate of region to the inequity of health status of rural poor residents in Shaanxi province is $24.3803 \%$, which indicates that differences lie in the equity of health status of rural poor residents from different regions. The contribution rate of marital status, age, economic level, and gender to the inequity of health status is positive, indicating that it increased the inequity of health status of rural poor residents which was sloped towards the richer. In terms of income status, the contribution rate of $2.6281 \%$, indicated that residents with a higher family income status have better health status. Different targeted poverty alleviation policies have different impacts on the equity of rural poor residents' health status. The contribution rate of the industry development, employment helping, health poverty alleviation, and basic living standard guaranteeing to health status inequity was $6.8580 \%, 1.7984 \%$, $10.7070 \%$, and $0.2016 \%$, respectively, which suggested that these policies may do more to improve the health status of the richer residents. However, the contribution rate of relocation policy to the inequity of health status is $-3.8396 \%$, which indicated that the relocation policy was more conducive to improving the health status of poorer residents.

Table 5 Decomposition of health inequity of the rural poor residents in Shannxi provine 


\begin{tabular}{|c|c|c|c|c|}
\hline Variables & Elasticity coefficient & Concentrati-on index & Contribution & $\begin{array}{l}\text { Contribution } \\
\text { Rate(\%) }\end{array}$ \\
\hline Income & 0.0020 & 0.4314 & 0.0009 & 2.6281 \\
\hline Region(Baseline: Shanbe & & & & -24.3803 \\
\hline Guanzhong & -0.1000 & 0.0832 & -0.0083 & -25.4225 \\
\hline Shannan & -0.0436 & -0.0078 & 0.0003 & 1.0422 \\
\hline \multicolumn{5}{|l|}{ Gender(Baseline: Male) } \\
\hline Female & 0.0023 & -0.1117 & -0.0003 & -0.8101 \\
\hline Age(Baseline: Age $<31$ ) & & & & 15.9273 \\
\hline $30<$ Age $<61$ & -0.2154 & 0.0431 & -0.0093 & -28.4331 \\
\hline Age $>60$ & -0.1313 & -0.1104 & 0.0145 & 44.3604 \\
\hline \multicolumn{3}{|c|}{ Education(Baseline: Unschooled) } & & 32.5702 \\
\hline Primary school & 0.0395 & 0.0489 & 0.0019 & 5.9044 \\
\hline Middle school and above & 0.0471 & 0.1851 & 0.0087 & 26.6658 \\
\hline \multicolumn{3}{|c|}{ Marital status(Baseline: Unmarried) } & & 17.5964 \\
\hline Married and cohabiting & 0.0747 & 0.0960 & 0.0072 & 21.9468 \\
\hline Divorced or widowed & 0.0076 & -0.1866 & -0.0014 & -4.3504 \\
\hline \multicolumn{5}{|c|}{ Participation in industrial development(Baseline: No) } \\
\hline Yes & 0.0905 & 0.0248 & 0.0022 & 6.8580 \\
\hline \multicolumn{5}{|c|}{ Participation in relocation(Baseline: No) } \\
\hline Yes & -0.0058 & 0.2179 & -0.0013 & -3.8396 \\
\hline \multicolumn{5}{|c|}{ participation in transfer employment(Baseline: No) } \\
\hline Yes & 0.0035 & 0.1700 & 0.0006 & 1.7984 \\
\hline \multicolumn{5}{|c|}{ Enjoying the health poverty alleviation project(Baseline: No) } \\
\hline Yes & -0.0596 & -0.0588 & 0.0035 & 10.7070 \\
\hline \multicolumn{5}{|c|}{ Enjoying basic living standard guaranteeing(Baseline: No) } \\
\hline Yes & -0.0572 & -0.1152 & 0.0066 & 0.2016 \\
\hline R.E. & & & & 59.2544 \\
\hline Sum & & & 0.0258 & 100 \\
\hline
\end{tabular}


The decomposition results of health status concentration index of rural poor residents in the different regions of Shaanxi province, Shanbei, Guanzhong, and Shannan, are shown in Table 6[see additional file 1]. In Shanbei, the most significant contributors to health status inequity of rural poor residents were the relocation policy (-121.1139), the degree of education (115.6037\%), and economic level (114.2978\%), which suggests that the degree of education increased the inequity of health status which is sloped towards the richer, the residents with a higher economic level were more likely to be in a better health status, and relocation policy was more conducive to improving the health status of poorer residents. The contribution rate of industry development (-5.9095\%), employment helping (-1.4973\%), health poverty alleviation $(-36.6318 \%)$, and basic living standard guaranteeing $(-76.1106 \%)$ to the inequity of health status of rural poor residents is all negative. In Guanzhong, the most significant contributors to the inequity of health status of rural poor residents were age (16.4410\%), economic level (14.2025\%), and the basic living standard guaranteeing (12.3163\%). In Shannan, the most significant contributors to the inequity of health status of rural poor residents were the degree of education (26.5094\%), economic level (16.8537\%), and the basic living standard guaranteeing (16.0547\%).

By comparing the contribution rates of different variables to the inequity of the health status of rural poor residents in different areas of Shaanxi province, it can be found that although the most significant factors in different regions were not identical, economic level and the degree of education were both important factors affecting the inequity of health status, both having positive contribution rates. It is indicated that the rural poor residents with a higher economic level were likely to be in a better health status and the degree of education increased the pro-rich inequity of health status. The effects of the targeted poverty alleviation policy on the inequity of health status of rural poor residents in different regions of Shaanxi province were different.

\section{Discussion}

We used the sampling survey data of rural poor residents in Shaanxi province in 2017, and found that while the economic level of rural poor residents was low (mean $=13395.11 \pm 374.99$ yuan), the overall health status of residents was poor, and the proportion of poor or very poor health status by a selfevaluation was as high as $44.56 \%$. Through chi-square test analysis, it is found that there were significant differences in the health status of rural poor residents in different regions of Shaanxi province, and there were significant correlations between economic level, the degree of education, marital status, age, and health status. There were significant differences in the health status of rural poor residents who participated in industry development, relocation, enjoyed the health poverty alleviation policy, and basic living standard guaranteeing policy. According to the calculations of the concentration index of rural poor residents' health status and its decomposition, we found that there was an inequity sloped towards the richer for health status. Economic level, and the degree of education were the most important factors influencing the inequity of health status, and the targeted poverty alleviation policy had an important influence on the inequity of health status of rural poor residents. 
The research found that the degree of education of rural poor residents in Shaanxi was very low. In terms of the overall situation of Shaanxi province, $31.99 \%$ of rural poor residents had no schooling, and just $5 \%$ of rural poor residents had a high school education degree or above. The proportion of rural poor residents in Shanbei who had no schooling was as high as $64.58 \%$. The degree of education is an important component of residents' individual development ability. In the framework of the family sustainable livelihood analysis, education is an important component of livelihood capital [32], and it has a profound impact on the livelihood choices of rural families and their living conditions. A transnational study showed that education is a leading factor of income inequity [33], and poverty has a negative impact on the quantity and quality of education development, which is can lead to poverty [34]. The research results showed that poor residents with a lower degree of education are likely to have a poorer health status, and the association was significant in age groups where $30<A g e<61$ and Age $>60$. For a long time, the relationship between education and health has been highly concerned by researchers $[35,36]$. Receiving a higher degree of education has a positive impact on the healthy lifestyle and utilization of health-care of individuals, thus affecting individual health status. Although the current evaluation and identification standard of rural poor residents in China involves a comprehensive target, family income is still an important factor affecting the development of other aspects. There is a complex and close relationship between income, health, and the degree of education. Education and health play a critical role in poverty reduction [37], which shows that a higher economic level is conducive to a better education investment and health level.

It is found that the marital status of rural poor residents in Shaanxi province has a significant impact on their health status, and the health status of married cohabitation residents is significantly better than that of unmarried, divorced, or widowed residents. It has been found that marital status influences individual health status through mediating variables such as social psychological stress [38]. A study from South Korea added to the evidence that an individual's health behavior and disease status are linked to marital status [39]. In China's social context, family economic level is closely related to men's marital status, and adult men from poor families have a weaker position in the marriage market. According to the definition of forced male bachelors in rural areas [40], unmarried men aged 28 and above in rural areas are called forced male bachelors. The marriage squeeze has a significant negative impact on men's quality of life [41]. The forced male bachelors in our survey accounted for $11.31 \%$ of all the rural poor male residents, and the proportion of these men with poor health status is as high as $67 \%$. Therefore, we can come to the conclusion that there is also a close link between poverty, marriage, and health status.

There was an important finding showing a significant relationship between participation in the targeted poverty alleviation programs and the health status of rural poor residents. First, according to the results of the chi-square test, the health status of the poor residents who participated in industry development was significantly better than that of the poor residents who did not participate in industry development. After controlling the influence of age on the health status and participation in industry development, the difference was still significant. There are two ways to explain this result. One is that poor residents increase their household income by taking part in industry development, which is conducive to improving their health status; another is that poor health status is not conducive to poor residents' participation in 
industry development. Participation in relocation has a similar impact on the health of poor residents as does the participation in industry development. Therefore, it can be concluded that poor residents with poor health status have difficulties in achieving poverty alleviation by participating in industrial development and relocation, and poor health status has become an important factor restricting the development of individuals and families. Second, data analysis results showed that the health status of rural poor residents who enjoyed the health poverty alleviation project and basic living standard guaranteeing project may be worse off. This is because the residents with a poor health status have a higher utilization rate of medical services and medical expenses, and the majority of the poor residents who enjoy the basic living standard guaranteeing project are those who lack the ability to work. In turn, this reflects the support and protection of the targeted poverty alleviation policy to the weak, and also reflects the "targeted" of the policy design.

Another issue of great importance is that under the background of implementing the targeted poverty alleviation policies, there was an inequity sloped towards the richer in the health status of rural poor residents in Shaanxi province and different regions. Leading that the higher the family economic level is, the better the health status of the residents may be. Although the Chinese government has long been committed to promoting health equity of different groups through the reform of the medical security system, economic level inequity has always been an important factor affecting the equity of the utilization of health services and health status of residents [22]. Although the health poverty alleviation project is conducive to reducing the medical burden of rural poor residents, it is still based on the new rural cooperative medical system, which cannot completely eliminate the impact of the family economic level on the equity of the utilization of health care services for rural poor residents [42]. Economic level and the degree of education are the most important factors affecting the equity of health status of rural poor residents, and the degree of education is also an important reason for personal development and family income. The results of the decomposition of the health status concentration index of rural poor residents in Shaanxi province showed that the policies of industry development, employment helping, health poverty alleviation, and basic living standard guaranteeing all increased the inequity of the health status sloped towards the richer. At the same time, the effect of the poverty alleviation policy on the equity of health status of rural poor residents in Shanbei was different from Guanzhong and Shannan. The variables of industry development, relocation, employment helping, health poverty alleviation, and basic living standard guaranteeing projects all increased the inequity of the health status sloped towards the poorer. Due to the rural resident's income gap being higher in Shanbei, and the targeted poverty alleviation policies have a more significant effect on the income, results in the increase and health improvement of residents with a poor economic level.

Above all, it can be concluded that although the targeted poverty alleviation policy promotes the income increase of rural poor residents through industrial development and other measures, improves the health through poverty alleviation, and implements the basic living standard guaranteeing project, the benefits from these policies will impact different people in unequal ways, and the sustainable development of poor residents will also be different. Specifically, improving the ability of the sustainable development of the rural poor residents is the long-term goal of the targeted poverty alleviation policy, and the 
development-oriented policies, such as industry development and employment helping, are conducive to enhancing the development ability of poor residents by increasing their incomes and through other approaches. However, residents with poor health status are in a weak position during the participation process of these policies, and the positive impact of these policies in turn is weakened. An effective measure to ensure the sustainable development ability of residents in poor health conditions is an important issue that needs to be considered to improve the effect of the targeted poverty alleviation policies in the future.

\section{Strengths and limitations}

This research draws from a rare concern and discussion on the health and health equity of rural poor residents in the context of China's targeted poverty alleviation policy. Additionally, factors affecting the health status and health equity of rural poor residents were studied by using first-hand survey data, and the research conclusion can significantly improve the effect and equity of the targeted poverty alleviation policy. But there are also some limitations: first, the situation of rural poor residents in different areas of China cannot be equally compared. Due to the difficulty of obtaining data of rural poor residents, we only use the survey data of Shaanxi province for analysis. In the following research, we will focus on the situation of different provinces. Second, health equity is a complex concept. This paper only considered the equity of health status based on given results, but did not consider the utilization of health services from rural poor residents. Through the self-evaluation of health, this can reflect an individual's whole health status, but result deviation caused by subjective reasons is inevitable. Third, this study focused on the impact of the participation in the targeted poverty alleviation policies on the equity of the health status of rural poor residents, but didn't involve the factors that may affect the health equity in the implementation process of the targeted poverty alleviation policies, which will lead towards another research question. Finally, with the in-depth implementation of the targeted poverty alleviation policy, its impact on the health status of rural poor residents is seen as a dynamic process. The next step is to focus on the dynamic mechanism of the targeted poverty alleviation policy's impact on the health status of rural poor residents, which may be more meaningful.

\section{Conclusion}

This study showed that the rural poor residents in Shaanxi province have a poor health status and low degree of education, with a high proportion of forced male bachelors. The health status of rural poor residents was significantly correlated by family economic level, the degree of education, and marital status, and whether to participate in industry development, relocation, health poverty alleviation, and utilizing the standard guaranteeing project. The research found that there was an inequity sloped towards the richer on the health status of rural poor residents, the family economic level, and the degree education level, which were the most important factors affecting the health status of poor residents. The targeted poverty alleviation policy had an important impact on the health equity of rural poor residents, thus deeply affecting their sustainable development ability. Under the current targeted poverty alleviation policy system, poor residents with poor health status are faced with the double dilemma of increasing 
family economic income and improving health status, which is shown as the key needed to consolidate and improve the targeted poverty alleviation effect. Therefore, through more scientific and rational policy design, the economic level and health status of poor residents with poor health status should be developed simultaneously, and the equity of policies benefiting different poor residents should be guaranteed, so as to prevent the occurrence of new relative poverty.

\section{Declarations}

\section{Abbreviations}

Not applicable.

\section{Ethics approval and consent to participate}

Ethics approval for this study was given by the medical ethics committee of Health Science Center of Xi'an Jiaotong University (approval number 2016-416). Approved by the ethics committee, we obtained verbal consent from study participants. Prior to the survey, we informed the survey contents in detail and assured them that the data were for research only.

\section{Consent for publication}

Not applicable.

\section{Availability of data and material}

The data used in this study belong to our research team, and data does not involve any personal privacy information. Other authors who want to use the data may contact the author.

\section{Competing interests}

The authors declare that they have no competing interests.

\section{Funding}

This study was fund by the Major Projects of Philosophy and Social Science Research of the Ministry of Education (18JZD045), Humanities and Social Science Talent Plan of Shaanxi Province, and Young Talent Support Plan of Xi'an Jiaotong University. The funding bodies had no further involvement in the research process, and they will continue to fund follow-up research.

\section{Authors' contributions}

$X D, L W$ and YR participated in the design and conceptualization of the study. XD and LW reviewed literature. XD and YR analyzed the data and interpreted the statistical results. XD drafted the manuscript. LW and YR were involved in revising the manuscript critically. All of the authors have read, revised and approved the final manuscript. 
Acknowledgements

Thanks to the summer holiday social practice program of Xi'an Jiaotong University for the help in data collecting, and also thanks to the college students who participated in the program for their efforts to survey. Any student participating in the survey can use the data for research.

\section{Authors' details}

School of Public Policy and Administration,Xi'an Jiaotong University,

No 28 Xianning West Road,Xi'an 710049,Shaanxi,China

\section{References}

1. Bloom D , Canning D . The Health and Poverty of Nations: From theory to practice.Journal of Human Development, 2003; 4(1):47-71.

2. Wagstaff A . Poverty and health sector inequalities. Bull World Health Organ, 2002; 80(2):97-105.

3. Cohen B E, Reutter L. Development of the role of public health nurses in addressing child and family poverty: a framework for action. Journal of AdvancedNursing, 2010; 60(1):96-107.

4. Sen A. Why health equity? Health economics. 2002;11(8):659-66.

5. Wang B, Zhu Y. Summary of 40 Years of Anti-poverty Experience in Rural China Since Reform and Opening-up--Historical Inevitability and Long Term of Targeted Poverty Alleviation. Journal of Northwest A \& F University. 2018. http://kns.cnki.net/kns/brief/default_result.aspx

6. Dummer TJB, Cook IG. Exploring China's rural health crisis: Processes and policy implications. Health Policy. 2007;83(1):1-16.

7. Zhang H, Xu Z, Sun C, Elahi E. Targeted poverty alleviation using photovoltaic power: Review of Chinese policies. Energy Policy. 2018;120:550-8.

8. Zhou Y, Guo Y, Liu Y, Wu W, Li Y. Targeted poverty alleviation and land policy innovation: Some practice and policy implications from China. Land Use Policy. 2018;74:53-65.

9. GAO J-m, BO Q-j, HE D-g. Satisfaction of targeted poverty alleviation policies and its influencing factors based on farmers' perspective: Questionnaire survey and research on 1720 farmers in Shaanxi Province of China. Ecological Economy. 2017(1):5.

10. Yan-Han LI, School WR. Research on the Demographic Characteristics and Targeted Poverty Alleviation Effect of Entrepreneurial Poverty Alleviation Targets. Pioneering with Science \& Technology Monthly. 2017.

11. WANG L,YE X,CHEN J. Performance evaluation of industrial poverty alleviation from the perspective of precise recognition. Chinese Journal of Population Resources and Environment,2018;28(01):113- 
123. http://kns.cnki.net/KCMS/detail/detail.aspx?

dbcode=CJFQ\&dbname=CJFDLAST2018\&filename=ZGRZ201801013\&uid

12. Chen Sheng,Pan Hong,Lu Jing. Case Study on Factors Influencing the Performance of Accurate Poverty Alleviation. CHINESE PUBLIC ADMINISTRATION,2016(09):88-93.

13. Li Y, Su B, Liu Y. Realizing targeted poverty alleviation in China: people's voices, implementation challenges and policy implications. China Agricultural Economic Review. 2016;8(3):443-454.

14. Wang J, Chen Y, Yan M. Research on the Targeted Measures of Poverty Alleviation and Its Innovative Ways in China. Bulletin of the Chinese Academy of Sciences. 2016;31(3):289-295.

15. Zhou Z, Su Y, Gao J, Benjamin C, Zhu Z, Ling X, et al. Assessing equity of healthcare utilization in rural China: results from nationally representative surveys from 1993 to 2008. International Journal for Equity in Health. 2013;12(1):34-

16. Ling Z. Effects of Rural Medical Financial Assistance in China. China \& World Economy. 2010;15(2):16-28.

17. Zeng Y, Li J, Yuan Z, Fang Y. The effect of China's new cooperative medical scheme on health expenditures among the rural elderly. International Journal for Equity in Health. 2019;18(1).

18. Braveman P. Health disparities and health equity: Concepts and measurement. Annual Review of Public Health. 2006;27:167-94.

19. Tao Y, Henry K, Zou Q, Zhong X. Methods for measuring horizontal equity in health resource allocation: a comparative study. Health economics review. 2014;4(1):10-.

20. Konings P, Harper S, Lynch J, Hosseinpoor AR, Berkvens D, Lorant V, et al. Analysis of socioeconomic health inequalities using the concentration index. International Journal of Public Health. 2010;55(1):71-4.

21. Zhou Z, Gao J, Fox A, Rao K, Xu K, Xu L, et al. Measuring the equity of inpatient utilization in Chinese rural areas. Bmc Health Services Research. 2011;11.

22. Su M, Zhou Z, Si Y, Wei X, Xu Y, Fan X, et al. Comparing the effects of China's three basic health insurance schemes on the equity of health-related quality of life: using the method of coarsened exact matching. Health and Quality of Life Outcomes. 2018;16.

23. Konings $P$, Harper S, Lynch J, Hosseinpoor AR, Berkvens D, Lorant V, et al. Analysis of socioeconomic health inequalities using the concentration index. International Journal of Public Health. 2010;55(1):71-74.

24. Wagstaff A. On decomposing the causes of health sector inequalities with an application to malnutrition inequalities in Vietnam. Washington D. 2001;112(1):207-223.

25. Rabin R, De-Charro F. EQ-5D: a measure of health status from the EuroQol Group. Annals of Medicine. 2001;33(5):337-343.

26. Yu H, Zhang H, Yang J, Liu C, Lu C, Yang H, et al. Health utility scores of family caregivers for leukemia patients measured by EQ-5D-3L: a cross-sectional survey in China. BMC Cancer. 2018;18(1):950. 
27. Devlin NJ, Brooks R. EQ-5D and the EuroQol Group: Past, Present and Future. Appl Health Econ Health Policy. 2017;15(2):127-137.

28. Zhang YE, Liu Z, Cheng L, University N. Does China's New Rural Pension Scheme Improve the Life Quality of the Rural Elderly? China Economic Quarterly. 2016.

29. LI D,ZHOU Z,ZHAO D. Health inequity among rural elder residents in Shaanxi province,2013.Chinese Journal of Public Health,2019(1):1-5. http://kns.cnki.net/KCMS/detail/21.1234.R.20190115.2059.032.html

30. Bhandari PB.Rural livelihood change? Household capital, community resources and livelihood transition. Journal of Rural Studies.2013;32(4):126-136.

31. Lorraine PJ, Hammock RL, Blanton JM. Predictors of self-rated health status among Texas residents. Preventing Chronic Disease. 2005;2(4):A12.

32. Hesketh T, Ye X, Li L, Wang H. Health status and access to health care of migrant workers in China. Public Health Reports. 2008;123(2):189.

33. De Gregorio J, Lee JW. Education and Income Inequality: New Evidence from Cross-Country Data. Social Science Electronic Publishing.2010; 48(3):395-416.

34. Knight J, Shi L, Quheng D. Education and the poverty trap in rural China. Oxford Development Studies. 2009;37(4):311-332.

35. Ross CE, Wu C. The links between education and health. American Sociological Review.1995;60(5):719-745.

36. Cutler D, University H, Llerasmuney, Adriana, University P. Education and Health: Evaluating Theories and Evidence. Nber Working Papers. 2008;10(2):129-138.

37. Gounder R, Xing Z. Impact of education and health on poverty reduction: Monetary and nonmonetary evidence from Fiji. Economic Modelling. 2012;29(3):787-794.

38. Joung IMA. Marital Status and Health Problems. Encyclopedia of Stress. 2007(2):653-659.

39. Kim A, Lee JA, Park HS. Health behaviors and illness according to marital status in middle-aged Koreans. Journal of Public Health. 2018;40(2):e99-e106.

40. Zhou XD, Wang XL, Li L, Hesketh T. The very high sex ratio in rural China: Impact on the psychosocial wellbeing of unmarried men. Social Science \& Medicine. 2011;73(9):1422-1427.

41. Yang X, Li S, Attané I, Feldman MW. On the Relationship Between the Marriage Squeeze and the Quality of Life of Rural Men in China. American Journal of Mens Health. 2017;11(3):702-10.

42. Yan J, Ren Y, Zhou Z, Xu T, Wang X, Du L, et al. Research on the horizontal equity of inpatient benefits among NCMS enrollees in China: evidence from Shaanxi Province. BMC Health Services Research.18(1).

\section{Supplementary Files}

This is a list of supplementary files associated with this preprint. Click to download. 
- revisedadditionalfile1.doc 